\title{
Resource Nexus Perspectives towards the UN Sustainable Development Goals
}

Accepted revised version after reviews and editor's decision for Nature Sustainability as of 3 Oct 2018

Debate around increasing demand for natural resources is often framed in terms of a "nexus" and perhaps at risk of becoming a buzz word. A nexus between what, at what scales, and what would be the consequences? This article analyses why readers should care about the nexus concept towards the SDGs. We discuss a five-nodes definition and propose perspectives that may lead to a reload of climate policy with buy-in from supply chain managers and resourcerich developing countries. Our research perspectives address modelling approaches and scenarios at the interface of bio-physical inputs with the human dimensions of security and governance. 
Demand for natural resources has grown rapidly for decades, and is expected to continue growing, causing severe repercussions, risks, and threats for humans and ecosystems at different scales. Implementing the 17 United Nations Sustainable Development Goals (SDGs) may come with additional demands. Accordingly, managing resources in a more sustainable manner and comprehensive approaches accounting for the interdependencies of resource use are needed ${ }^{1}$. The recent debate on a "resource nexus" addresses such interlinkages.

The aims of this paper are to examine the nexus debate and to develop a research perspective on how a better understanding of resource interlinkages can be utilized to deliver the SDGs in an unprecedented integration. In doing so, we will discuss the ability of a nexus approach to assess critical interlinkages across five natural resource categories - water, energy, food, materials, and land - along their value chains, and to enable sustainable resource use pathways, in particular with a view on the SDGs on food (SDG 2), water (SDG 6), energy (SDG 7), cities (SDG 11), production and consumption (SDG 12). The novel contribution is the clarification of nexus perspectives, in particular towards the SDGs, and the modelling of SDGs from a policy-relevant perspective.

The sections are organised as follows: section two examines the nexus debate, provides a definition and concludes on a next generation of nexus research addressing scales and contexts. Section three illustrates our perspective via three potential pathways and discusses new metrics for comparative research. It explores modelling the nexus towards the year 2030 when the SDGs ought to be delivered and beyond. In line with our transdisciplinary approach, this section discusses the need for new scenarios at the interface of bio-physical resource inputs with the human dimensions of security and governance. Finally, we conclude on useful directions for nexus research and the SDG delivery.

From our viewpoint, the nexus concept should be applied in a flexible manner across multiple scales and does not offer a panacea. However, it will boost integration beyond what has been achieved so far, and can help achieving national and regional sustainable development goals, and promoting wellbeing, health and equity across space. It is our opinion that nexus research can be aligned with a public purpose, helping to overcome silo-thinking and reduce the risks of tradeoffs across the SDGs.

\section{Examining the resource nexus debate}

\section{The need for more integrated approaches}

In the past, resource governance mostly focused on single resource categories such as water or energy along a supply chain that ran from primary natural resource, through processing, distribution and final consumption and disposal. The nexus concept ${ }^{2-5}$ was formulated in response to such "silo" thinking, emphasizing the examination of critical interlinkages across resources, particularly synergies and trade-offs, in a more integrated manner.

The nexus debate has been quite vivid over recent years, especially in international organisations. Much research has been done on regional case studies. However, conceptual clarity often is lacking. Studies assessed perceptions of business ${ }^{6}$ and performed stakeholder analysis on the use 
of the term ${ }^{7}$ - yet without moving forward on a perspective. So, has the nexus now become a 'buzzword,' as a recent editorial in Nature suggests ${ }^{8}$ ?

We propose to define the resource nexus as a set of context-specific critical interlinkages between two or more natural resources used in delivery chains towards systems of provision for water, energy, food, land, and materials.

Figure 1: The Nexus: Interlinkages across Resources and SDGs
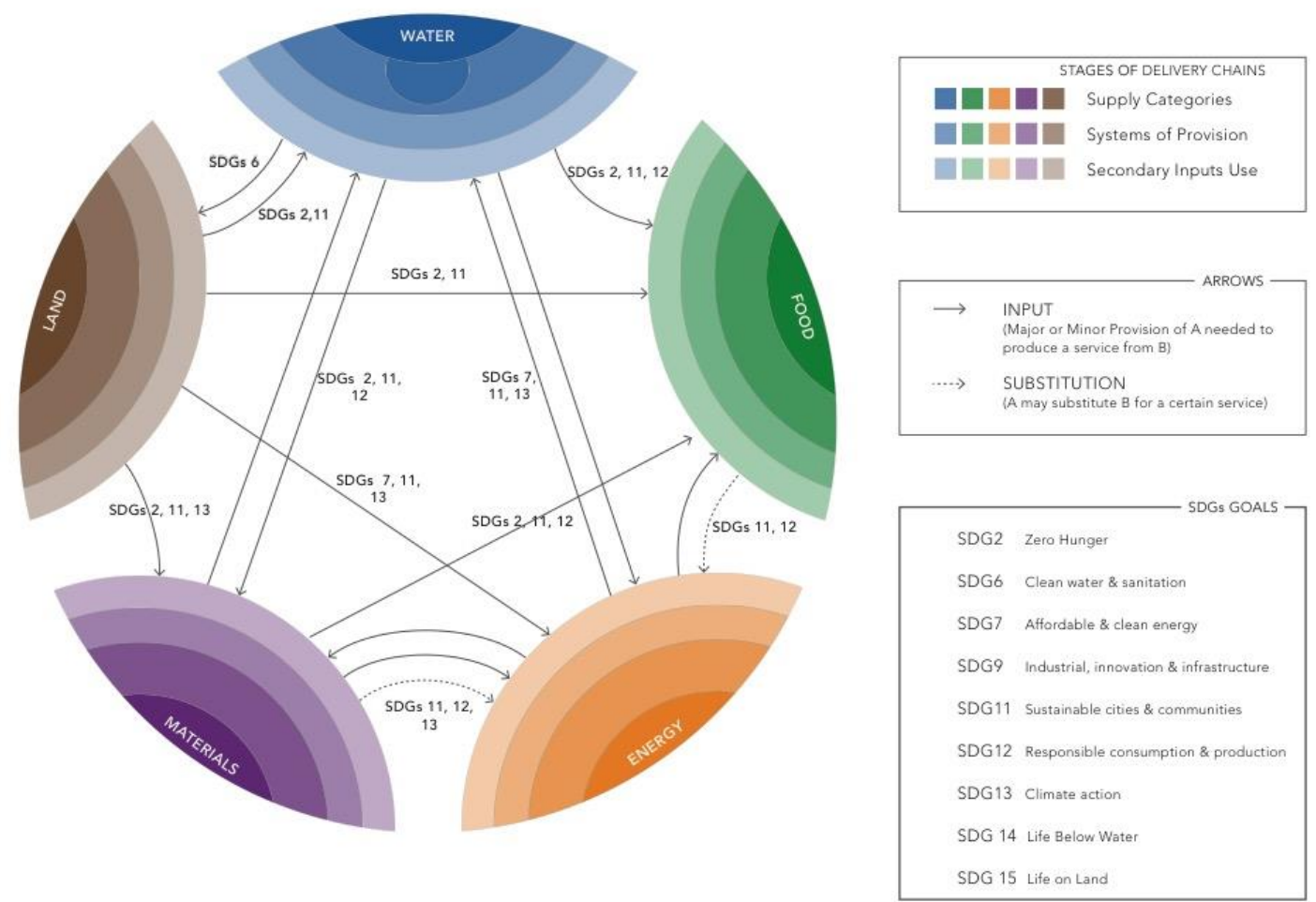

(Source: Own compilation) This figure describes main interlinkages across using resources. For instance, water is used to produce energy and vice versa. The figure displays main resource inputs into the chains of other resources at three main delivery stages that are illustrated through different shades: primary production; systems of provision through production, distribution, and consumption; and potential secondary use. Arrows and directions indicate relevant SDGs. The figure describes a five-node approach although less dimensions might be feasible too after a screening stage, in order to reduce complexities.

Figure 1 illustrates main interlinkages in a generic manner. Some interlinkages may be more obvious than others, such as the connection between food and water. Others have become more critical through rapid recent changes, such as the materials needed for energy production. Figure 1 also proposes to analyse the delivery chains from nature to consumers for each resource and its connection with SDGs. Accordingly, the figure introduces layers addressing primary production, the socio-economic supply systems and their distribution, as well as recycling and reuse. The latter is well established for a number of materials and industrial water use, and 
broadening those activities is essential towards a circular economy. Critical interlinkages may occur between corresponding or different layers, as illustrated by energy needs for pumping water through distribution systems to end-users.

As pointed out ${ }^{9,10}$ such multifunctional approaches have a tradition, especially in forestry management and the Dublin principles on integrated water resource management (IWRM). Yet, integrated approaches are still an exception rather than the rule. In our fragmented world, attempts to integrate and actively seek for synergies are needed. Managing and governing such interlinkages is a key to achieve the SDGs - especially the cross-cutting SDG 12 on sustainable resource management. Such integrated approaches could also be applied when one resource (e.g. a forest) is managed for multiple and often conflicting goals, such as biodiversity, water management, community livelihoods, and timber production. Figure 2 illustrates the complexity of dealing with those SDGs and the manifold resource interlinkages; applying scores ${ }^{11}$ appears useful.

Figure 2: Main SDGs and the Nexus

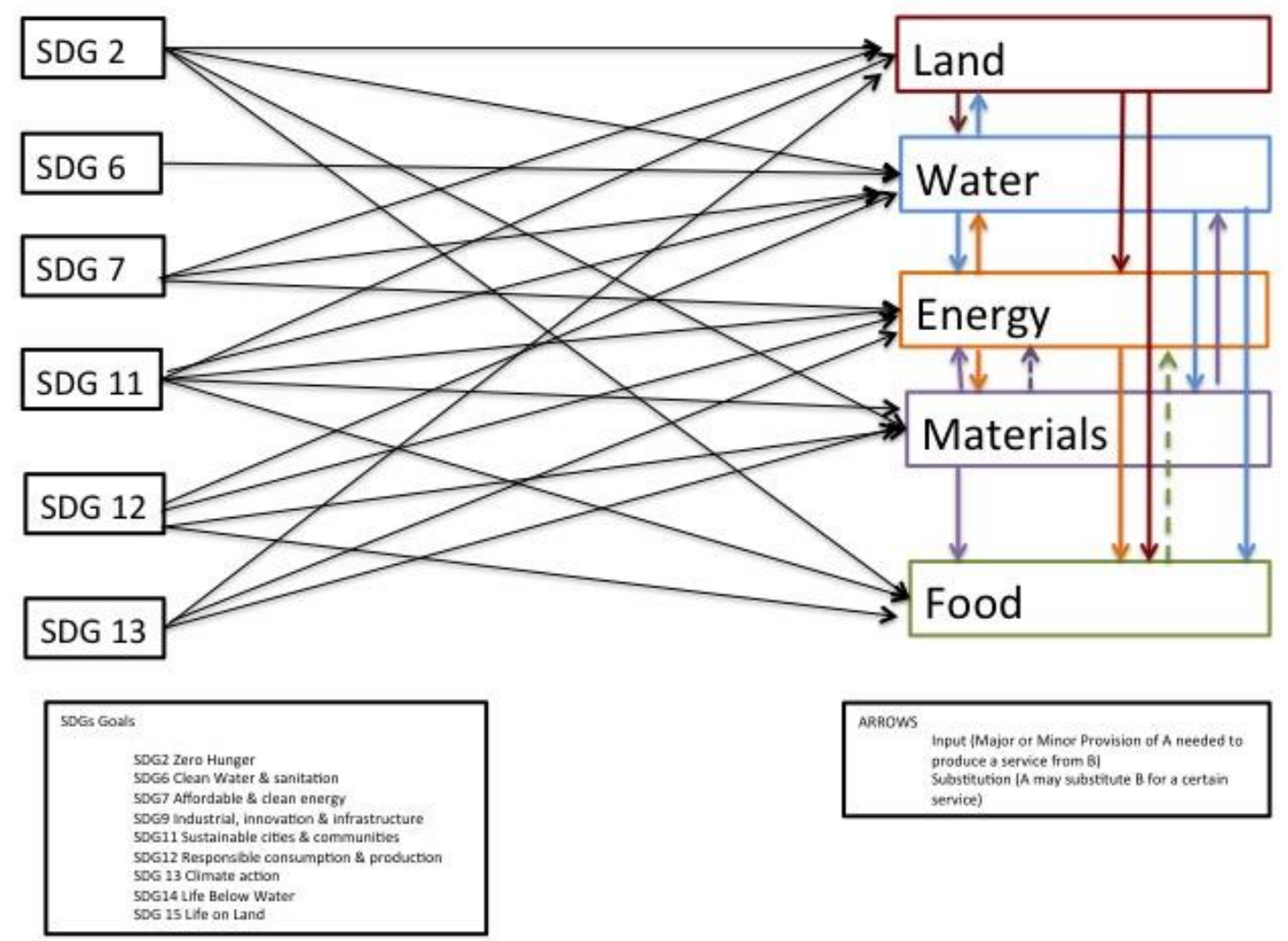

(Source: Own compilation) This figure describes main interlinkages between relevant SDGs and nexus categories. For instance, SDG 2 on zero hunger is relevant for land use, water use, materials (fertilizer), and indeed food. It also reiterates main interlinkages across using resources in line with figure 1. Arrows indicate directions as input into other resources or mutual substitutions. 


\section{A five node resource nexus approach}

Little agreement exists in the literature as to what natural resources are included in the resource nexus. The most widely acknowledged nexus approach covers water-energy-food ${ }^{3,12}$, or water - energy ${ }^{13}$. We propose to broaden the scope slightly and add land and materials.

In line with other scholars ${ }^{14-16}$, the inclusion of land in a resource nexus approach can be considered important because of its many critical environmental functions. Land provides a key supporting service for the formation of soil and other natural resources, for nutrient recycling and water production, regulation and purification, and it provides resources for livelihood and development. Figure 1 and 2 illustrate land as an input into all other categories, and its critical interlinkages with water. In scoping useful nexus approaches for implementation purposes, including land is essential to support SDGs $2,7,11,13,15$. Discussing land and food, the resilience of food systems is strongly dependent on functioning landscapes to provide water-based ecosystem services for agricultural production. The food system is essential for SDG 2, with inputs needed from all other resources and manifold critical interlinkages. Alternatively, having biomass as a dimension on its own is conceivable, in order to capture its relevance for food, for bioenergy, and for bio-based materials from forestry and others. In Figure 1 biomass is part of food, energy, and land, illustrating the interlinkages and putting more emphasis on the systems of provision rather than primary resources itself.

In line with ${ }^{17}$, we also propose to include materials for at least four reasons. First, materials are strongly linked to the other resource categories. Base metals, critical minerals and construction minerals have significant implications for energy production and distribution (SDG 7) ${ }^{20}$, water provision (SDG 6) and urbanization (SDGs 9+11). Mineral fertilizers are also inputs for food production (SDG 2). Second, non-energy, non-renewable resources account for about $50 \%$ of natural resource use in most industrialized countries measured in physical units according to methodology of material flows analysis measured in physical units according to methodology of material flows analysis, see e.g. ${ }^{18,19}$. Third, the costs associated with purchasing and processing materials in manufacturing industries have been about $40 \%$ of gross production costs throughout the $2000 s^{21,22}$. Lastly, base metals and nutrients cause particularly significant environmental impacts, including land and water degradation and GHG emissions ${ }^{23}$, and assessing agriculture with optimal mineral inputs can well be a strength of nexus research.

Such a five-node nexus comes with advantages of consistency, comprehensiveness and policy relevance. It acknowledges wider environmental functions of water, land and soil as regulating and stabilizing the provision of inputs from other resources, such as biomass for food production. It retains advantages of addressing SDGs 2, 6, and 7, and is potentially stronger in addressing SDGs 9, 11, 12 and 15 than other approaches. We acknowledge the potential disadvantages of growing the nexus model from two or three dimensions to a five-node one given that adding dimensions inevitably increases complexity in the model. However, utilizing a five-node nexus can be done in a flexible manner during a scoping process about systems of interest and may lead to research focusing on two or three dimensions rather than five. One may also note the straightforwardness of a nexus concept addressing and quantifying inputs, while additional complexity comes in through acknowledging boundaries of biosphere integrity and risk multipliers such as health and climate change ${ }^{24}$. Like Liu et al., ${ }^{25}$ we propose that understanding 
the realities and complexities of human-environment systems and related environmentdevelopment goals as specified in the SDGs is the key objective of nexus research.

\section{Multiple scales and securities}

A significant number of regional nexus studies has been undertaken, for instance on Brazil ${ }^{26}$ South and Southeast Asia ${ }^{27,28}$, Asia and the Pacific ${ }^{29}$, the MENA region ${ }^{30}$, southern Africa ${ }^{31}$, and others. Chatham House ${ }^{32}$ and the Transatlantic Academy ${ }^{4,5}$ stress the security dimension - in terms of both traditional national and inter-state security and a much broader human security agenda $a^{3,5,32,33}$.

While previous research has focused on risks of a resource curse and resource conflicts, interest now turns toward assessing linkages to the security-related aspects of climate change, public health ${ }^{34}$, and a host of vexing justice and equity-related concerns. Traditional and human security concerns are thus central to SDG implementation. Polycentric governance, as explored by Elinor Ostrom ${ }^{35}$ and her many followers, bring advantages of adaptability, more effective social learning and increased legitimacy towards a new generation of global governance approaches. We conclude on the usefulness of such research in a comparative perspective.

For future nexus research we propose more research across scales ${ }^{36}$ and securities; doing so will require assessing various institutional contexts and a number of critical interlinkages for both ecosystems and human actors. In some cases, criticalities might be particularly strong for human actors (e.g. risks of extended electricity outages), in others for ecosystems.

\section{Perspectives towards delivering the SDGs}

\section{Three new pathways}

A nexus approach seems well-suited in the development of new pathways, by assessing tradeoffs and identifying synergies across scales. Such trans-disciplinary efforts, encompassing and integrating various disciplines and involving a wide range of stakeholders ${ }^{37}$, hold promise for new knowledge creation on how scales and contexts can be integrated in nexus research. The three areas of climate change, supply chain management, and resource-rich countries may serve as illustrations.

After the Paris agreement on climate change (2015), nexus research could potentially improve implementation of Nationally Determined Contributions (NDCs) by building synergies among climate mitigation and adaptation and more sustainable economic development. Afforestation for climate mitigation should become more integrated with sustainable water regulation, so that subsequent water yields ${ }^{38}$ do not counteract climate adaptation efforts and compromise communities' water security. Similarly, risk assessment for bioenergy plantations, unconventional hydrocarbons, hydropower and CCS technologies should include water criteria as practiced in a number of strategic environmental impact assessments. Enhancing soil carbon in agriculture may synergistically serve climate mitigation and adaptation, by sequestering carbon from the atmosphere, while simultaneously reducing fertilizer and irrigation demand and enhancing drought resilience. Multi-functional systems such as agro-forestry adapted to local contexts can increase local co-benefits across climate adaptation and mitigation and other 
natural resources ${ }^{39}$; and must be assessed against potential productivity losses. Also, adapting to increased water scarcity through desalination of seawater can advance mitigation goals, if driven by renewable energy. Regarding our proposed scope of the nexus, more sustainable pathways for cement and stee ${ }^{40}$ and other base materials are relevant. Altogether, this is a perspective to relate SDG 13 on climate change with peoples' concerns, as represented through SDGs 2, 6, 7, 9, $11,12,15$, and others. As the next section proposes, developing suitable integrated dynamic models can support such perspective.

In another pathway, a nexus approach could support relating SDG 12 on responsible production and consumption with business understanding of risks ${ }^{6}$ and international supply chain management efforts. A nexus concept can enable a wider understanding of resource efficiency towards a circular economy at a variety of scales ${ }^{41}$. Doing so would offer benefits for manufacturing industries, firstly through reducing the costs of purchasing and processing natural resources $21,42,43$ and, secondly, to innovate along entire supply chains, introducing novel products and systems. The nexus concept adds at least two useful features:

- A life-cycle wide and international approach addressing different resource-intensities and efficiencies of each processing step along and across supply chains, to reduce total water, land, carbon and other footprints ${ }^{44}$.

- A more comprehensive approach to critical resource use thresholds, supported by quantitative and spatially explicit nexus assessment tools.

Future nexus research could facilitate the SDG resource efficiency targets $(8.4,9.4,11 . b, 12.2)$ and support implementation of SDGs 2, 6, 14.

In a third perspective, resource-rich developing countries could benefit. Up to now they tend to have a low resource efficiency performance compared to world average ${ }^{19}$, even declining over time in cases like the MENA region ${ }^{45}$. A nexus approach could offer opportunities e.g. for Australia ${ }^{46}$ :

- Assessing the wider resource input requirements for mining and processing;

- Supporting integrated assessments for future planning across sectors and (potentially scarce) resources;

- Establishing 'soft extraction' pathways that increase revenues for countries, yet minimize cross-resource input requirements, and develop suitable, context-specific integrated policy options.

In our view, a nexus approach would complement ongoing natural resource governance efforts and help countries and communities establish inclusive and green growth pathways (SDG 9). Doing so nexus research could draw lessons from livelihood research ${ }^{47}$, participatory approaches and regional cases. In the long-run possible guidelines for planetary mineral consumption ${ }^{48}$ could also be supported.

\section{Resource input coefficients for key interlinkages}

Such nexus research across scales and addressing contexts will have a data dimension in developing resource input coefficients. While such coefficients are often studied separately, 
consistent coefficients across a five-node nexus are a research frontier. A sensible next step would be to undertake a few studies on a limited number of critical interlinkages among resources $\left.{ }^{23,49-51}\right\}$ for key sectors and materials. Existing databases from FAOSTAT as well as from research should allow for a robust approximation. Particular attention must be paid to contextspecific deviations from global average cross-resource input intensities and interlinkages. The Group on Earth Observation (GEO) has proposed a Global Earth Observation System of Systems (GEOSS) that might be useful for the future.

Sankey diagrams in a circle might be a good way to visualize interlinkages ${ }^{52}$. Several indicators can be combined into a single index and visualized in a radar graph. Fig 3 below is a radar graph visualizing the impact of an intervention on systems of provision against the background of the already existing pressure compared to reference countries higher (green), similar (yellow) or lower (red) sustainability than a given context. The area of the polygon indicates the impact of the intervention: the larger the area, the bigger the impact. The usefulness of our life-cycle wide nexus approach with layers along supply chains can be illustrated via hydro-dams, which require assessing the evaporation of dams and the risks of electricity blackouts downstream. One will note the relevance of scales here as water areas tend to differ from electricity systems. Another case illustrating our five-node nexus is sand, where a 'looming tragedy' is being observed that connects demand from construction activities, international trade (partly illicit) with losses in land use and ecosystem services ${ }^{53}$.

Figure 3: Critical interlinkages of using resources for specific systems

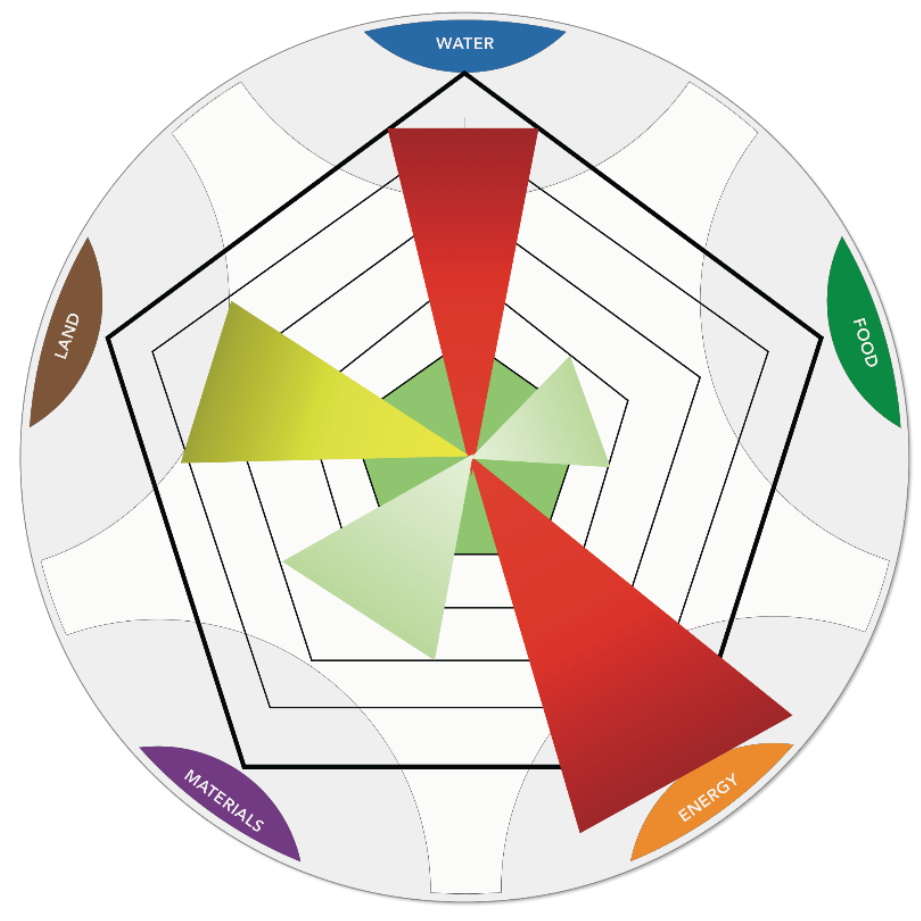


(Source: Own compilation) The figure describes generic criticalities across using resources within a radar graph. It illustrates a significant criticality (in red) that potentially transgresses critical limits for the case of energy use and one for water use that is close to such limits. In this figure, food and materials are less critical (in green). The figure underlines the relevance of doing research on such critical interlinkages compared with analysing simple trends, and the option of focusing on relevant interlinkages after a screening process.

Over time, such resource input coefficients might become part of international hubs - an aim of UNEP's International Resource Panel and Future Earth - and facilitate integrated planning as well as modelling and new scenarios. In such perspective, more criticality assessments across scales and assessing both environmental and human security could be incorporated.

\section{Modelling Perspectives}

Modelling is relevant to analyse and assess complexities in delivering SDGs via a nexus approach. Yet, in an inter- and transdisciplinary effort one should be aware of simplifications, assumptions, and limitations. Dialogue is also necessary to train researchers and practitioners from the nonmodelling world, and to communicate across realms. Systems thinking and complexity theory offer useful approaches.

Vertically consistent regional, national, to local policy planning can be obtained through hierarchical nesting of models or consistent soft linkage methodologies. Downscaling routines may be used for quick scan visual interpretation of much coarser modelling results. Downscaling is useful for linking with integrated assessment models. However, downscaled results typically cannot be used for decision processes or choices of policy instruments operating at higher scales. Thus accompanying research on multi-level, polycentric resource governance (including trade) seems useful, ideally in a dialogue with modelling efforts to inform choices and planning evidence.

In addition, modelling can also be deployed across temporal scales. This is relevant for the SDG time perspective of 2030 and beyond, modelling anthropogenic stocks and access to secondary resources. Clearly, in a nexus context, treatment of time preferences across all resources and environmental goods and services is a relevant research area. For example, a climate mitigation strategy expressed by an endogenously determined carbon price might lead to large-scale deployment of bioenergy, thereby creating pressure on land, water, and food systems in the second half of the century, as well as implications for biosphere integrity. Approaching this from a nexus perspective is relevant to more integrated risk assessment processes and developing response strategies.

Bio-physical models already describe several natural resources included in the five-node nexus discussed above, particularly water, energy, biomass and land. They exist at various scales, including global Integrated Assessment Models. Minerals and materials are not yet well represented in such models, and there is a lack of socio-economic variables. However, they can be extended and are useful for trend analysis, impact assessments and reviews (see figure 4).

System dynamics approaches allow the testing of a novel hypothesis and determination of trade-offs and other impacts. It facilitates understanding of the dynamics of coordination between different factors and relationships between environmental resources. Through such an 
approach, research may address regional and sub-regional non-linear dynamics such as $U C L$ IDA3/IDA5 ${ }^{26}$, and add interactions between such factors as climate change impacts and government policies in order to identify suitable strategies.

Industrial ecology models assess societal metabolism in physical terms (i.e. flows and stocks of materials and energy); they are technology-specific and relevant for industrial sectors and supply chains. Among recent developments is the emergence of Life Cycle Sustainability Analysis, a framework trying to be more policy relevant by including economic and social aspects, forward looking research, and upscaling ${ }^{54}$.

Recent socio-economic work uses environmentally-extended Input Output Analysis to incorporate water, food, land and particularly energy ${ }^{55}$. Computable General Equilibrium (CGE) models such as ENV-Linkages (OECD) coupled with integrated assessment models such as the IMAGE model (PBL) or UCL ENGAGE, and other hybrid approaches, may prove suitable for analysing economy-wide implications of resource use interlinkages and trends (see figure 4), despite yet lacking some of the technological details.

A number of tools have been developed to support planning and management ${ }^{56}$. The Water Evaluation and Planning (WEAP) and the Long-range Energy Alternatives Planning (LEAP) have led to a new tool, the WEAP-LEAP framework, which is beginning to become integrated with a land use ${ }^{16,57}$. A step forward towards more integrated planning is the climate, land-use, energy and water (CLEW) modelling framework ${ }^{58} 59$.

\section{Towards future scenarios}

Soft interlinkages across these models and planning tools is pertinent ${ }^{60,61}$ - alongside and in interaction with stakeholders ${ }^{62}$. In our view, nexus research has a responsibility and a capability to engage with stakeholders through consultations, transformative workshops and tailored discussion papers. Such co-production of knowledge is a key ingredient towards accomplishing SDGs. It is also important to keep in mind that contemporary modeling often suggests conclusions based on optimal and efficient scenarios, while in reality second-best options prevail, unexpected shocks occur, and management is often more of a muddling through. Models thus are important to simplify understanding of interlinkages and assess the complexity of new directions, together with communication, interaction and learning. This way research can generate future missions that can be ambitious, activate innovation across sectors, across actors and across disciplines, and enable bottom-up solutions and experimentation.

A structured comparative approach to case studies will be useful to gain additional understanding of the variety of critical intersections and will help to develop 'shock scenarios' (figure 4), for instance about water and food crises contributing to social unrest, political instability and/or violence. Given the variety of possible resource futures around the globe, based on real-world imperfect choices, we also suggest the development of new 'business as usual scenarios' incorporating different lessons from history and long-term time series, and likely climate change impacts and other transgressions of planetary boundaries in the future. Indeed, evaluations of strategies via modelling impact assessments need to be part of such a set, all done in an iterative manner. 
Figure 4 illustrates that those different types of scenario processes can be aligned with stages of decision-making processes. It also suggests that a variety of scenario analysis approaches are yet to be developed in future nexus research.

Figure 4: A Set of scenarios supporting decision-making processes

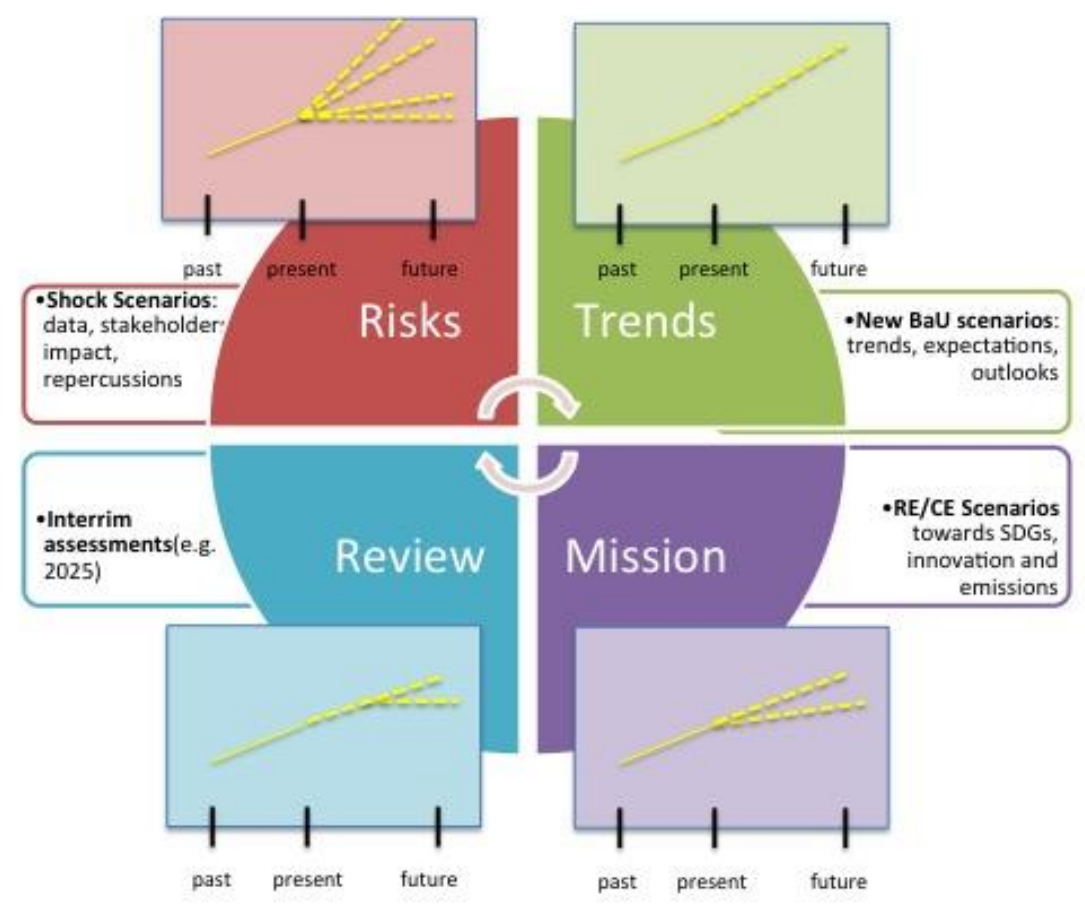

(Source: Own compilation.) The figure describes four novel types of scenarios that are relevant for nexus research. 'Risks' may include shocks, e.g. if critical limits are being transgressed. 'New BaU' scenarios may include ongoing environmental changes and expected saturation trends. 'Review' refers to measures taken and their assessment towards goals and gaps. 'Missions' would refer to new and ambitions scenarios more likely to meet goals and attract multiple actors.

\section{Outlook}

This paper addresses concerns over future resource demand and the delivery of the SDGs in an integrated manner. It develops a definition for nexus research, centred around critical interlinkages between using two or more natural resources as inputs into socio-economic delivery chains. Referring to a five nodes nexus of water, energy, food, land, and materials, we also underline the relevance of scales and contexts, and the need for flexible applications ${ }^{63}$. Our perspective suggests new conceptual underpinnings at the interface of environmental research 
with human security and strategic choices to enable a new generation of pathways, planning tools, scenarios, and modelling towards delivering the SDGs.

In the short run, nexus research could help SDG planners overcome silo mentality and enable more synergistic approaches. Being aware of doing so is easier said than done, research should provide key coefficients and help developing new missions, pathways and roadmaps. Such perspectives seek more impactful research with actors from business, other stakeholders and involvement of developing countries, moving from necessary conditions for risk assessment toward more likely conditions for success in large and more complex systems.

Over time, integrated planning for systems of water, energy and food provision - as well as for land use and extractive activities - and new scenarios can be developed, all supported by better modelling capacities and an enhanced understanding of how those approaches interact with governance in the real world. We may imagine a reload of climate policy and more emphasis on water, food and land, all with more enthusiasm from supply chain managers and resource-rich developing countries.

Through adding resource inputs, interlinkages and governance, knowledge on the nexus thus complements and strengthens existing sustainability research on the anthropocene, on planetary boundaries, and on earth systems governance that typically follows a more top down oriented approach, and it also complements environmental research on natural capital. It also connects well to research on anthropogenic stocks ${ }^{64}$, and ongoing debates about a circular economy that yet need to reach out to development concerns.

Finally, this paper stresses the role of research in challenging times. It endorses a view on SDGs and broader sustainability ambitions that stresses inclusive development for the poor and towards improved international relations. As much as we consider a nexus approach as indispensable to deliver the SDGs it should seek to apply academic rigour on data, evidence, and modelling, as well as disseminate, upscale and generalize findings via missions and pathways across fora and scales. Nexus research could become salient for the integrated, effective and efficient implementation of SDGs.

\section{Citations}

1 Le Blanc, D. Towards integration at last? The sustainable development goals as a network of targets. Sustainable Development 23, 176-187 (2015).

2 Bleischwitz, R., Hoff, H., Spataru, C., Van der Voet, E. \& VanDeveer, S. D., eds, Routledge Handbook of the Resource Nexus. (Routledge, 2017).

This comprehensive and up-to-date Handbook presents a detailed international review of current knowledge and thinking on the resource nexus from an inter-disciplinary perspective, with 32 chapters addressing tools and metrics, modelling, political economy, a number of cases across different scales, and governance responses.

3 Hoff, H. Understanding the Nexus (Background paper for Bonn 2011 Conference: The Water, Energy and Food Security Nexus). (Stockholm Environment Institute, 2011). 
4 Andrews-Speed, P. et al. The Global Resource Nexus: The Struggles for Land, Energy, Food, Water, and Minerals. 90 (Transatlantic Academy, Washington, DC, 2012).

5 Andrews-Speed, P. et al. Want, waste or war? : the global resource nexus and the struggle for land, energy, food, water and minerals. (Routledge/Earthscan, 2015).

6 Green, J. M. H. et al. Research priorities for managing the impacts and dependencies of business upon food, energy, water and the environment. Sustainability Science, 1-13, doi:10.1007/s11625-016-0402-4 (2016).

7 Cairns, R. \& Krzywoszynska, A. Anatomy of a buzzword: The emergence of 'the waterenergy-food nexus' in UK natural resource debates. Environmental Science \& Policy 64, 164-170 (2016).

8 Nature. Editorial: Scientific buzzwords obscure meaning: 'Nexus' is enjoying new-found popularity. But what does it actually mean? Nature 538 (2016).

9 Graedel, T. E. \& v.d. Voet, E. Linkages of sustainability. (MIT Press, 2010).

10 Wichelns, D. The water-energy-food nexus: Is the increasing attention warranted, from either a research or policy perspective? Environmental Science \& Policy 69, 113-123, doi:http://dx.doi.org/10.1016/j.envsci.2016.12.018 (2017).

11 Nilsson, M., Griggs, D. \& Visbeck, M. Map the interactions between Sustainable Development Goals. Nature 534, 320-323 (2016).

12 Bazilian, M. et al. Considering the energy, water and food nexus: Towards an integrated modelling approach. Energy Policy 39, 7896-7906, doi:http://dx.doi.org/10.1016/j.enpol.2011.09.039 (2011).

13 Howells, M. \& Rogner, H.-H. Water-energy nexus: Assessing integrated systems. Nature Climate Change 4, 246-247 (2014).

14 Ringler, C., Bhaduri, A. \& Lawford, R. The nexus across water, energy, land and food (WELF): potential for improved resource use efficiency? Current Opinion in Environmental Sustainability 5, 617-624, doi:http://dx.doi.org/10.1016/j.cosust.2013.11.002 (2013).

15 Sharmina, M. et al. A nexus perspective on competing land demands: Wider lessons from a UK policy case study. Environmental Science \& Policy 59, 74-84, doi:http://dx.doi.org/10.1016/j.envsci.2016.02.008 (2016).

16 Obersteiner, M. et al. Assessing the land resource-food price nexus of the Sustainable Development Goals. Science Advances 2, doi:10.1126/sciadv.1501499 (2016).

17 Mo, W. \& Zhang, Q. Energy-nutrients-water nexus: Integrated resource recovery in municipal wastewater treatment plants. Journal of Environmental Management 127, 255267, doi:http://dx.doi.org/10.1016/j.jenvman.2013.05.007 (2013).

18 Bringezu, S. \& Bleischwitz, R., eds, Sustainable resource management:Global trends, visions and policies. (Greanleaf Publishing, 2009).

19 Wiedmann, T. O. et al. The material footprint of nations. Proceedings of the National Academy of Sciences, doi:10.1073/pnas.1220362110, doi:doi:10.1073/pnas.1220362110 (2013).

20 Tokimatsu, K. et al. Energy modeling approach to the global energy-mineral nexus: A first look at metal requirements and the $2^{\circ} \mathrm{C}$ target. Applied Energy 207, 494-509, doi:https://doi.org/10.1016/j.apenergy.2017.05.151 (2017). 
21 Bleischwitz, R. International economics of resource productivity - Relevance, measurement, empirical trends, innovation, resource policies. International Economics and Economic Policy 7, 227-244, doi:10.1007/s10368-010-0170-z (2010).

22 Wilting, H. \& Hanemaaijer, A. Share of raw material costs in total production costs. (PBL Netherlands Environmental Assessment Agency, The Hague, 2014).

23 Hertwich, E. et al. Assessing the Environmental Impacts of Consumption and Production: Priority Products and Materials. (UNEP, Nairobi, 2010).

24 Dodds, F. \& Bartram, J., eds, The Water, Food, Energy and Climate Nexus: Challenges and an Agenda for Action. (Earthscan/Routledge, 2016).

25 Liu, J. et al. Systems integration for global sustainability. Science 347, doi:10.1126/science.1258832 (2015).

26 Senger, M. \& Spataru, C. Water-energy-land nexus-Modelling long-term scenarios for Brazil. IEEE Computer Society, doi:10.1109/EMS.2015.47 (2015).

27 Mukherji, A. The energy-irrigation nexus and its impact on groundwater markets in eastern Indo-Gangetic basin: Evidence from West Bengal, India. Energy Policy 35, 64136430, doi:http://dx.doi.org/10.1016/j.enpol.2007.08.019 (2007).

28 Rasul, G. Food, water, and energy security in South Asia: A nexus perspective from the Hindu Kush Himalayan region $z^{\jmath}$. Environmental Science \& Policy 39, 35-48, doi:http://dx.doi.org/10.1016/j.envsci.2014.01.010 (2014).

29 UN ESCAP. Water, Food and Energy Nexus in Asia and the Pacific. (United Nations Economic and Social Commission for Asia and the Pacific, Bangkok, 2014).

30 Siddiqi, A. \& Anadon, L. D. The water-energy nexus in Middle East and North Africa. Energy Policy 39, 4529-4540, doi:http://dx.doi.org/10.1016/j.enpol.2011.04.023 (2011).

31 Conway, D. et al. Climate and southern Africa's water-energy-food nexus. Nature Clim. Change 5, 837-846, doi:10.1038/nclimate2735

http://www.nature.com/nclimate/journal/v5/n9/abs/nclimate2735.html\#supplementar y-information (2015).

32 Lee, B., Preston, F., Kooroshy, J., Bailey, R. \& Lahn, G. Resources futures. (Chatham House, London, 2012).

33 Adger, W. N. et al. in Climate Change 2014: Impacts, Adaptation, and Vulnerability. Part A: Global and Sectoral Aspects. Contribution of Working Group II to the Fifth Assessment Report of the Intergovernmental Panel on Climate Change (eds C.B. Field et al.) 755-791 (Cambridge University Press, 2014).

34 Lockwood, A. H. Heat Advisory: Protecting Health on a Warming Planet. (MIT Press, 2016).

35 Ostrom, E. Beyond Markets and States: Polycentric Governance of Complex Economic Systems. The American Economic Review 100, 641-672 (2010).

36 Johnson, C. \& VanDeveer, S. D. in Routledge Handbook of the Resource Nexus (eds R. Bleischwitz et al.) 50-62 (Routledge, 2017).

37 Cairns, R., Wilsdon, J. \& O'Donovan, C. Sustainability in Turbulent Times: Lessons from the Nexus Network for supporting transdisciplinary research, <http://www.thenexusnetwork.org/wp-content/uploads/2017/03/sustainability-inturbulent-times.pdf> (2017). 
This is the concluding 'lessons learned' paper from the UK network on the nexus with special relevance for setting up, managing and funding transdisciplinary research and capacity building.

38 Calder, I. R. Blue Revolution: Integrated Land and Water Resource Management. (Earthscan, 2005).

39 Verchot, L. V. et al. Climate change: linking adaptation and mitigation through agroforestry. Mitigation and Adaptation Strategies for Global Change 12, 901-918, doi:10.1007/s11027-007-9105-6 (2007).

40 Allwood, J. M. Transitions to material efficiency in the UK steel economy. Philosophical Transactions of the Royal Society A: Mathematical, Physical and Engineering Sciences 371, doi:10.1098/rsta.2011.0577 (2013).

41 Schroeder, P., Anggraeni, K. \& Weber, U. The Relevance of Circular Economy Practices to the Sustainable Development Goals. Journal of Industrial Ecology, doi:doi:10.1111/jiec.12732 (2018).

42 Dobbs, R., Oppenheim, J., Thompson, F., Brinkman, M. \& Zornes, M. Resource Revolution: Meeting the world's energy, materials, food, and water needs. (McKinsey Global Institute, New York, 2011).

43 Ellen MacArthur Foundation \& McKinsey \& Co. Towards the circular economy: Accelerating the scale-up across global supply chains. (World Economic Forum, Geneva, 2014).

44 Galli, A. et al. Integrating Ecological, Carbon and Water footprint into a "Footprint Family" of indicators: Definition and role in tracking human pressure on the planet. Ecological Indicators 16, 100-112, doi:http://dx.doi.org/10.1016/j.ecolind.2011.06.017 (2012).

45 Schaffartzik, A. et al. The global metabolic transition: Regional patterns and trends of global material flows, 1950-2010. Global Environ Chang 26, 87-97, doi:http://dx.doi.org/10.1016/j.gloenvcha.2014.03.013 (2014).

46 Hatfield-Dodds, S. et al. Australia is 'free to choose' economic growth and falling environmental pressures. Nature 527, 49-53, doi:10.1038/nature16065

http://www.nature.com/nature/journal/v527/n7576/abs/nature16065.html\#supplementaryinformation (2015).

47 Biggs, E. M. et al. Sustainable development and the water-energy-food nexus: A perspective on livelihoods. Environmental Science \& Policy 54, 389-397, doi:http://dx.doi.org/10.1016/j.envsci.2015.08.002 (2015).

This paper makes a strong pledge on the relevance of livelihoods for nexus research, thus complementing the various research realms about quantitative tools and planning.

48 Nickless, E. Resourcing Future Generations: A global effort to meet the world's future needs head-on. European Geologist European Geologist 42, 46-50 (2016).

49 EEA. Environmental pressures from European consumption and production: A study in integrated environmental and economic analysis. (European Environment Agency, Copenhagen, 2013).

50 Karan, E., Asadi, S., Mohtar, R. \& Baawain, M. Towards the optimization of sustainable food-energy-water systems: A stochastic approach. Journal of Cleaner Production 171, 662-674, doi:https://doi.org/10.1016/j.jclepro.2017.10.051 (2018). 
$51 \quad K u r i a n, M$. The water-energy-food nexus: Trade-offs, thresholds and transdisciplinary approaches to sustainable development. Environmental Science \& Policy 68, 97-106, doi:https://doi.org/10.1016/j.envsci.2016.11.006 (2017).

This paper represents well the nexus interface between research on ecoystems and public services providing some statisctical tools and insights into governance.

52 Vivanco, D., Wang, R. \& Hertwich, E. Nexus Strength: A Novel Metric for Assessing the Global Resource Nexus. Journal of Industrial Ecology, doi:doi:10.1111/jiec.12704 (2017).

53 Torres, A., Brandt, J., Lear, K. \& Liu, J. A looming tragedy of the sand commons. Science 357, 970-971, doi:10.1126/science.aao0503 (2017).

54 Pauliuk, S., Arvesen, A., Stadler, K. \& Hertwich, E. G. Industrial ecology in integrated assessment models. Nature Clim. Change 7, 13-20, doi:10.1038/nclimate3148

http://www.nature.com/nclimate/journal/v7/n1/abs/nclimate3148.html\#supplementaryinformation (2017).

55 Calzadilla, A. et al. Climate change impacts on global agriculture. Climatic Change 120, 357-374, doi:10.1007/s10584-013-0822-4 (2013).

56 Daher, B. T. \& Mohtar, R. H. Water-energy-food (WEF) Nexus Tool 2.0: guiding integrative resource planning and decision-making. Water International 40, 748-771, doi:10.1080/02508060.2015.1074148 (2015).

57 FAO \& IIASA. GAEZ - Global Agro-Ecological Zones, <http://www.fao.org/nr/gaez/en/> (2017).

58 Hermann, S. et al. in 6th Dubrovnik Conference on Sustainable Development of Energy, Water and Environment Systems.

59 Flammini, A., Puri, M., Pluschke, L. \& Dubois, O. Walking the Nexus Talk: Assessing the Water-Energy-Food Nexus in the Context of the Sustainable Energy for All Initiative. (Food and Agriculture Organization of the United Nations, Rome, 2014).

60 Daher, B. et al. Developing Socio-Techno-Economic-Political (STEP) Solutions for Addressing Resource Nexus Hotspots. Sustainability 10, 512 (2018).

This excellent paper analyses resoure systems across scales; it comes up with critical questions about criticality, and develops insights into scenarios ('Iterative 3-Filter STEP Framework for Vetting WEF Nexus Scenarios').

61 Daher, B., Mohtar, R. H., Lee, S. H. \& Assi, A. in Water-Energy-Food Nexus: Principles and Practices Vol. 229 (eds P. Abdul Salam, Sangam Shrestha, Vishnu Prasad Pandey, \& Anil Kumar Anal) 57-67 (Wiley, 2017).

62 Pulver, S. \& VanDeveer, S. D. "Thinking About Tomorrows": Scenarios, Global Environmental Politics, and Social Science Scholarship. Global Environmental Politics 9, 113, doi:10.1162/glep.2009.9.2.1 (2009).

63 Stephan, R. M. et al. Water-energy-food nexus: a platform for implementing the Sustainable Development Goals. Water International 43, 472-479, doi:10.1080/02508060.2018.1446581 (2018).

64 Pauliuk, S., Wang, T. \& Müller, D. B. Steel all over the world: Estimating in-use stocks of iron for 200 countries. Resources, Conservation and Recycling 71, 22-30, doi:http://dx.doi.org/10.1016/j.resconrec.2012.11.008 (2013). 


\section{Full Author List}

1. Raimund Bleischwitz, Corresponding author, University College London, UCL ISR, UK, email: r.bleischwitz@ucl.ac.uk

2. Catalina Spataru, University College London, UCL Energy Institute, UK

3. Stacy D. VanDeveer, University of Massachusetts Boston, Department of Conflict Resolution, Human Security, and Global Governance, USA

4. Michael Obersteiner, International Institute for Applied Systems Analysis (IIASA), Austria

5. Ester van der Voet, Leiden University, Institute of Environmental Sciences CML, The Netherlands

6. Corey Johnson, UNC Greensboro, Department of Geography, Environment, and Sustainability, USA

7. Philip Andrews-Speed, National University of Singapore, Energy Studies Institute, Singapore

8. Tim Boersma, Columbia University, SIPA Center on Global Energy Policy, USA

9. Holger Hoff, Potsdam Institute for Climate Impact Research, Germany

10. Detlef P. van Vuuren, PBL Netherlands Environmental Assessment Agency \& Utrecht University, Copernicus Institute of Sustainable Development, The Netherlands

\section{Competing Interests Statement}

The authors declare no competing interests. 